\title{
Characteristics of Large Landslides and Application of Frequency Ratio Model for Susceptibility Assessment, Lower Jalal Catchment (Himachal Pradesh)
}

\author{
Vijendra Kumar Pandey ${ }^{1 *}$, Kaushal Kumar Sharma ${ }^{1,2}$, Suresh Kumar Bandooni ${ }^{3}$ \\ ${ }^{I}$ Centre for the Study of Regional Development, Jawaharlal Nehru University, New Delhi 110067 India \\ ${ }^{2}$ Department of Geography, Kirorimal College, University of Delhi, Delhi 110007 India \\ ${ }^{3}$ Department of Geography, SBS (Eve) College, University of Delhi, Delhi 110037 India
}

*Corresponding Author: Vijendra Kumar Pandey, Centre for the Study of Regional Development, Jawaharlal Nehru University, New Delhi, India

\begin{abstract}
:
Landslide susceptibility study is dealt to analyze the spatial probability of the phenomenon. This paper focused on the frequency ratio methods for producing landslide susceptibility map. A detailed landslide inventory with 36 landslide locations was prepared using the satellite imagery and field survey of the study area. Out of these 36 landslide locations, 12 of the sites surveyed and 24 landslides were identified using satellite imagery. DEM of the area prepared to analyze relief, aspect, and slope. Contour lines were digitized from the topographical map for the topographic analysis, geological map, land use, road network prepared into a geospatial data using the ArcGIS software. The predictive variables that influence slope instability such as slope angle, aspect, plan curvature, lithology, distance to faults, soil type, landuse, distance to road, distance to stream and dissection index were used for the landslide susceptibility modeling of the study area. The weightages of these variables were determined by the landslide frequency ratio (LFR) method, and sum of these variables is calculated as landslide susceptibility indices (LSI), which shows the severity of the phenomenon. The landslide susceptibility analysis was validated using the 20 landslide locations dataset. The validation results revealed that landslide susceptibility map has $87 \%$ accuracy for predicting the landslides in the study area.
\end{abstract}

Keywords: Landslide susceptibility, dissection index, rock strength, bulk density, slope instability.

\section{INTRODUCTION}

Landslide is one of the severe natural disaster that posse's serious threats to human lives and economic resources in the Himalayan regions of India. It has created significant constraints in the pace of economic development of the particular region; sometimes it completely bifurcates the region using transport communication at the specific period of times ${ }^{1}$. Its block road and cut-off the area particularly to a watershed which is sometimes served by a single route. In this regards, landslide susceptibility mapping provides a quantitative assessment of the spatial probability of the landslide occurrence $^{2}$. It is based on the understanding of complex geo-environmental processes and their controlling factors ${ }^{3}$. Precise landslide inventory dataset and appropriate modeling techniques are required for the analysis of landslide susceptibility ${ }^{4}$. Statistical methods have provided signification contribution to the development of spatial model and analysis of critical parameters under the circumstances they influence slope instability. The development of Geographic Information Systems (GIS) and statistical software allowing the integration of spatial and non-spatial models improve the modeling at various scales ${ }^{5}$. The recent development of remote sensing technology provides the user a detailed spatial analysis of macro-to-micro level details such as large-scale landslide to small debris fall, that is even smaller in dimension ${ }^{6}$. Sometimes there is a limitation of field data collection, particularly in that case mapping and data collection can be done using the satellite imagery for the inaccessible areas. Remote sensing data have been widely used for prediction of landslides ${ }^{7,8}$. The statistical methods, which are used for the susceptibility analysis includes; discriminant analysis ${ }^{5}$, 
multivariate statistics ${ }^{7,9}$, likelihood ratio $^{4,10}$, information value method $^{11}$, logistic regression methods $^{7,9-11}$ and binary logistic regression ${ }^{12}$. These methods analyses independent predictive variables that are controlling the landslide occurrence; regarding former landslides locations ${ }^{4,2,13}$.

However, statistical methods provide quantitative analysis of spatial parameters and do not incorporate its critical behavior which changes to space and time. The landslide susceptibility analysis studies which are based on geomorphic relationships with landsliding pattern and related morphological changes are very significant for the selection of varibles ${ }^{14-16}$. This year there is a large number of the studies on landslide susceptibility analysis using the combination of GIS data model and statistical, probabilistic models ${ }^{17-22}$. The remarkable method among these is fuzzy logic and artificial neural network models ${ }^{11,18}$. It was noted that susceptibility models that use combined neural and fuzzy weighting techniques produce good results ${ }^{23,24}$.

The factors that cause landslides are many, as it is the result of the complex geo-environmental processes, seismicity ${ }^{25}$, and sometimes unknown factors ${ }^{26}$. Particularly, slope stability assessment of human-modified slopes is done by rock mass strength classification ${ }^{27}$. Since there are many studies which proposed rock strength classification ${ }^{27-31}$. The objectives of the present study are to analyze the characteristics of the large landslides and analyze spatial of the probability of landslide in the study area. It was based on the qualitative assessment of the geomorphic process, i.e., surface dissection, drainage density, stream frequency, etc and human modification of the slope, particularly, landuse practices.

\section{STUDY AREA}

The study area is located in Sirmour district of Himachal Pradesh, India; and covers a $72.33 \mathrm{~km}^{2}$ area in rectangle shape of the Jalal watershed (Fig. 1). Geographically the area is located between $30^{\circ} 34^{\prime}$ $04^{\prime \prime}$ to $30^{\circ} 36^{\prime} 44^{\prime \prime}$ north latitude and $77^{\circ} 17^{\prime} 26^{\prime \prime}$ to $77^{\circ} 26^{\prime} 42^{\prime \prime}$ east longitude. Jalal River is a right bank tributary of Giri River. In the present study, Lower Jalal basin has been taken for the landslide susceptibility mapping, and detailed field investigation was carried between road corridors Jamta to Dadahu on Major District Road (MDR-1). The area was chosen due to its unique geological section of the region, including thrust, believed to be more prone to landsliding.

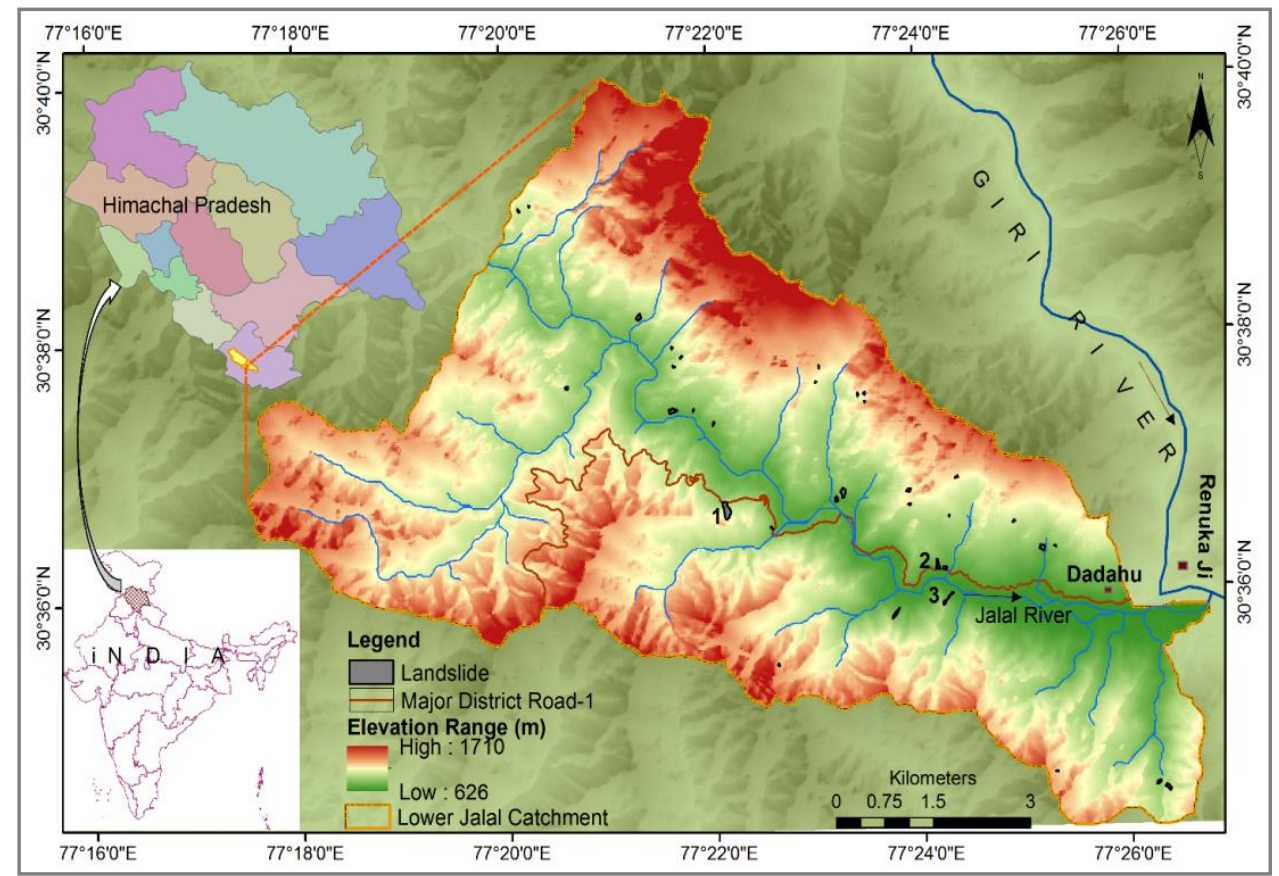

Fig1. Location map of Lower Jalal catchment in the Sirmour district of Himachal Pradesh (India).

The study area comprises of relatively recent fossiliferous sedimentary strata of largely unconsolidated sand, clay and conglomerates (unconsolidated material), which causes landslides and erosion. The main objective to study landslide occur along the road to understand its characteristics and mechanism of failures. Even the most carefully engineered highways suffer massive disruption due to landslide activity. The situation on more minor, less carefully constructed roads can be much 
worse. During the monsoon due to landslides, many towns and villages remain cut off for days while road contractor teams try to keep the network open, shoveling tones of landslides debris over the road edge. Here it accumulates as loose scree that damage vegetation chocks streams and creates a new zone of instabilities.

\section{MATERials AND METHOD}

In the present study Survey of India (SOI) topographic map on the RF 1:50000 and LANDSAT 8, sensor OLI/TIRS Path 147 Row 039 with a spatial resolution of 30m, LC81470392015322LGN00 Dated 18-11-2015 have been used. SRTM DEM 1 arc seconds was used for the topographic variables analysis. Landsat satellite image was used for the land use/ land cover mapping and preparation landslide inventory of the area.

\subsection{Landslide Inventory}

In the present study, the role of intrinsic and triggering factors that influence instability has been analyzed. In area 34 active landslides have been mapped during, April 2007 field investigation five major landslides have been surveyed between Jamta to Dadahu road section, and two sites have been selected for geotechnical investigation (Fig. 2). Landslide inventory map has prepared using detailed field survey along the road and interpretation of satellite imagery ${ }^{32}$. Landslides in the lower Jalal catchment has been analyzed using Geographic information system (GIS) and satellite imagery. GIS has played a key role in analyzing intrinsic factors that induce landslides and also used as basic attributes to landslide hazard modeling to identify the susceptible area.

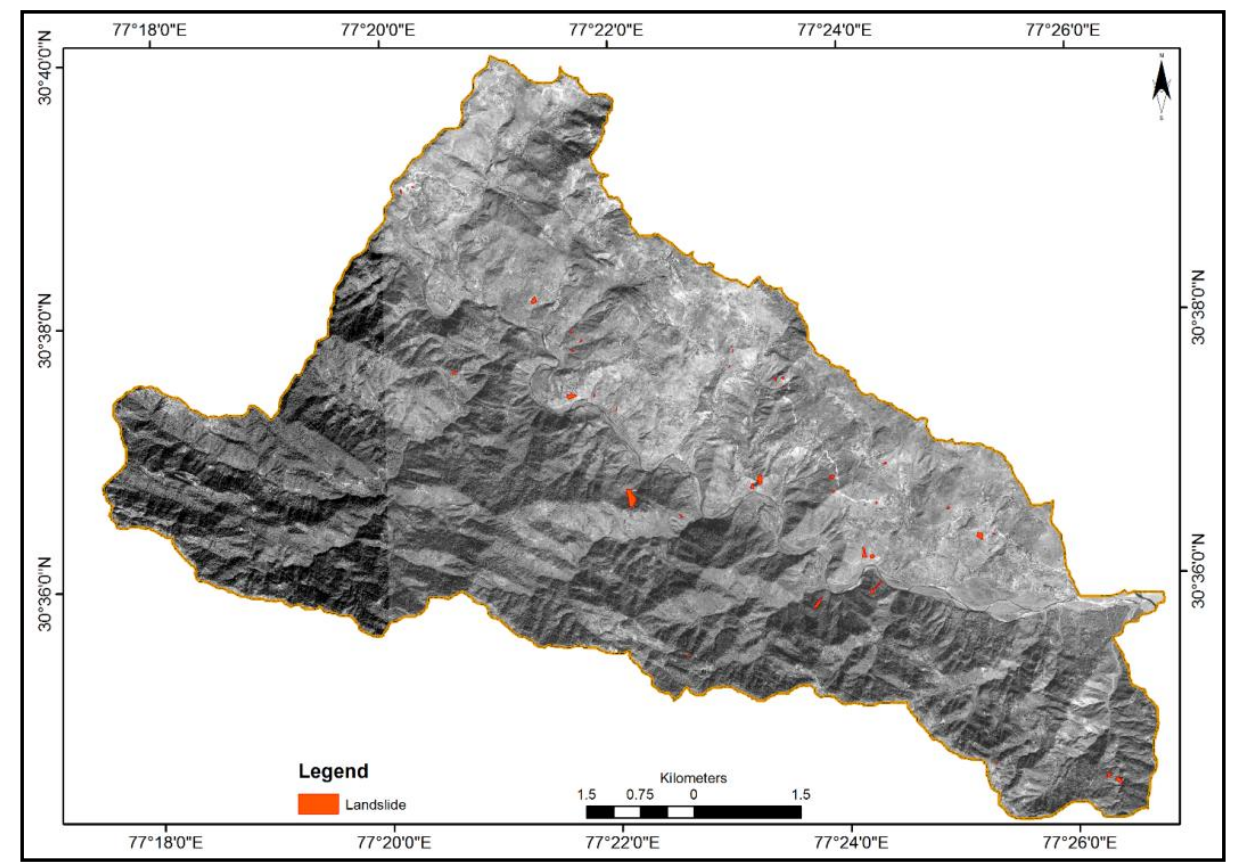

Fig2. Landslide Inventory map of the Lower Jalal Basin, 2015.

\subsection{Physical Setting of the Area}

\subsubsection{Geology}

The geological formation of the region is divisible into two main group; upper Proterozoic which includes rocks of undifferentiated Jaunasar groups and Paleozoic that is Dalhousie and equivalent granites and undifferentiated Tethyan sedimentary rock formations (Fig. 3d). Rock formations are occupying the region range in age from pre-Cambrian to Quaternary period. Lithology of the tertiary age with beds belonging to the carbonaceous system (Karol and Balani groups) on the northeast (Geological Survey of India, 2000). The Lower Tertiary rocks are well developed near the Dadahu. The Upper Tertiary or Shivalik formation developed near Nahan has a great mass of sandstone and conglomerates rocks. The Lesser Himalayas Tertiary rock formations include Karol, Balini, Jaunasar series largely made of carbonaceous shale, slate, dolomitic limestone, slates, schist, phyllite, quartzite rocks (GSI, 2000). 


\subsubsection{Aspect}

Aspect is analyzed as slope direction which controls solar insulation receives by the surface as average sunshine hours per day. Aspect is the crucial factor that induces slope instability. Aspect is significant variables that used for landslide susceptibility analysis ${ }^{14}$. It is directly related to the geochemical processes which operate on the slope and often causes slope instability. The area covered under different slope direction inclined to highest to the south facing slope which is $18 \%$ and subsequently followed by south-east slope direction $16.5 \%$ (Fig. 3b). Other directions such as north $10 \%$, east $5 \%$, west $7 \%$ and north-west $9 \%$ of the area of the catchment. This was found that it has a positive relationship with slope failures. Most of the slides that have occurred in the area has found in the southern slope direction.

\subsubsection{Slope}

Slope inclination of the study area is varying between $5^{\circ}-58^{\circ}$ (Fig. 3a). It is very crucial to assess slope instability that causes a landslide. Average slope distribution of study area shows that landslides frequently has occurred in the middle slope category that has covered $73 \%$ area of the catchment. Low slope category covers $5 \%$ and high slope inclined above $35^{\circ}$ covers $4.63 \%$.

\subsubsection{Geomorphological Characteristics}

Geomorphic features indicate that fluvial processes in the study area have gently slanted and somewhat undulated landscape, which are highly fragile to denudation process. The coarse sediments that are poorly cemented, loose gravelly deposits witness frequent debris fall. Fluvial and weathering processes firmly control the geomorphology of the basin with lithological formations.

\subsubsection{Drainage}

In the study area drainage density is very high along major streams and it has eroded the surface and induced landslides (Fig. 3c). The geomorphic analysis which is the ratio of high relief to low relief in a particular unit area shows that the area is moderately dissected (Fig. 3e). The moderately dissected area covers around 55\% and medium-high covers 38\% area, which is confined to the major river valleys and right bank of Jalal River. The high dissected area covers less than $1 \%$ of the Lower Jalal catchment.
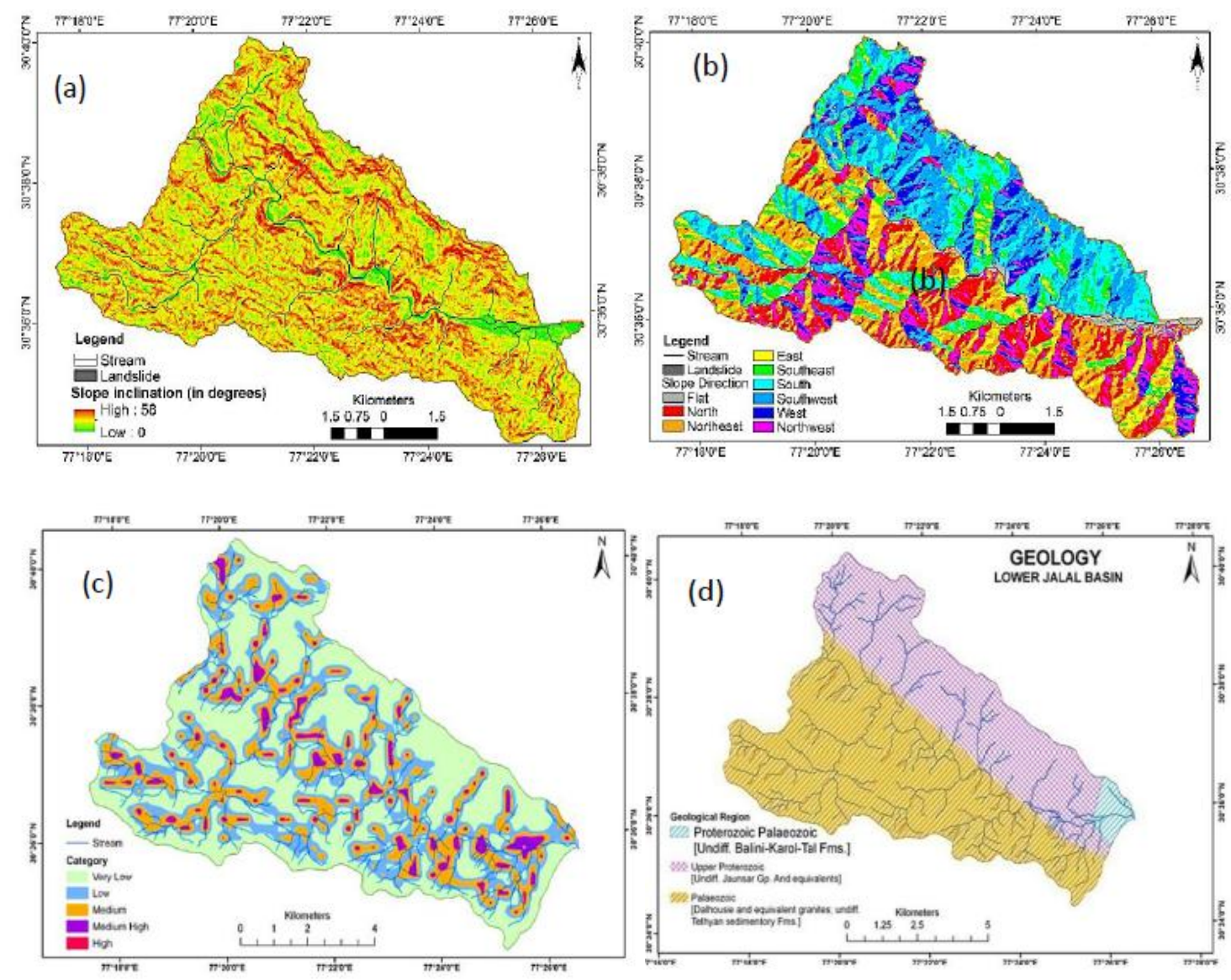

International Journal of Research in Geography (IJRG) 


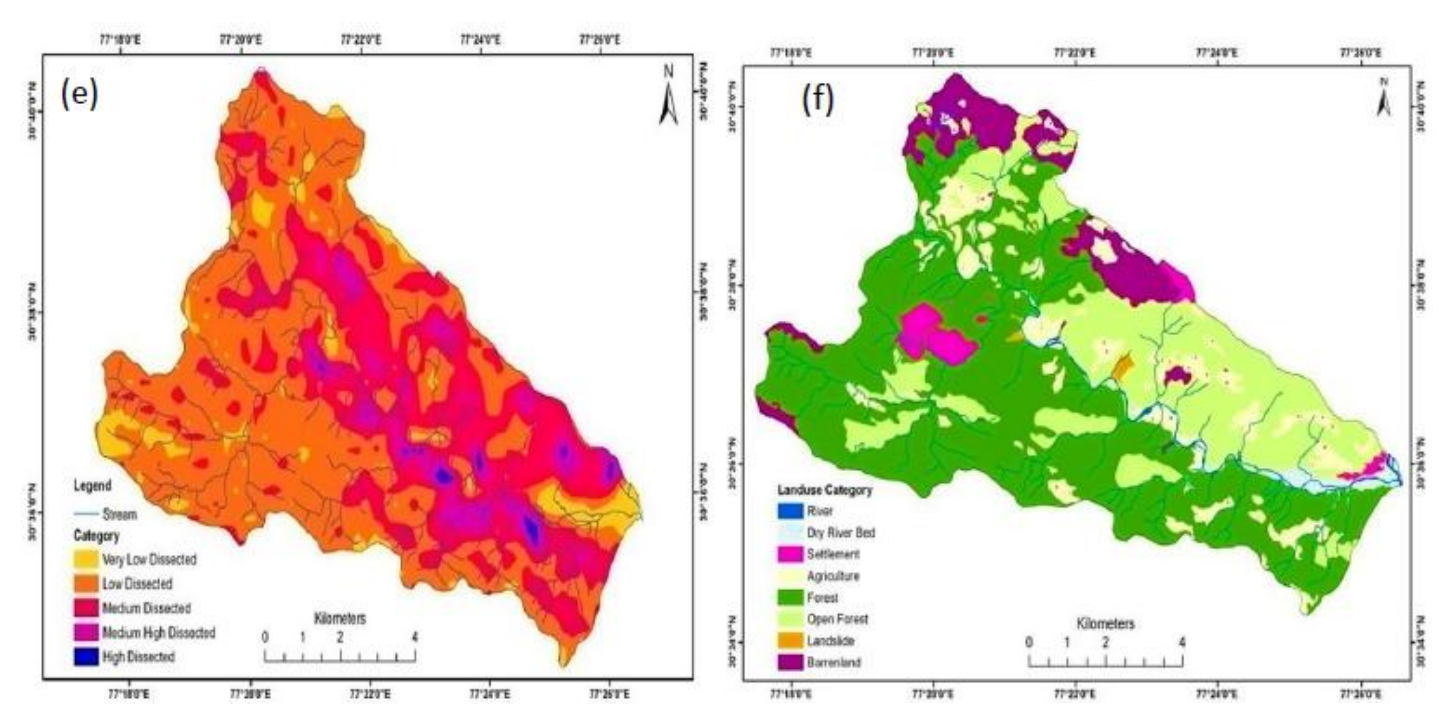

Fig3. Landslide susceptibility analysis selected predictive variables; (a) Slope inclination map; (b) Aspect map; (c) Geology map based on the Geological Survey of India (2000); (d) drainage density per square kilometer area, showing drainage network based on the Topographic sheet; (e) surface dissection map; and $(f)$ land use/land cover map.

\subsubsection{Landuse}

The landuse/ land cover has a direct relationship with slope instability that causes land degradation. Landuse map of the study area was prepared using the Landsat 8 satellite imagery of 2015, and validated using the google earth images (Fig. 3f). The catchment area is divided into two distinct landuse zones. The right side of Lower Jalal River is heavily forested and left side is dominated by agriculture practices, barren land, and open area. Forest covers approximately 58\%, and sparse forest covers $25.43 \%$ area; combined with around $83 \%$ area of the lower Jalal catchment. Agriculture land covers $10.34 \%$, subsequently, $7 \%$ covered by barren land, $2.5 \%$ settlement and $0.33 \%$ area covered by landslides.

\subsection{Landslide Susceptibility Mapping}

In the present study, an event-based 'landside frequency ratio (LFR)' model has been used to prepare landslide susceptibility index (LSI) of the area. Though, frequency ratio model has successfully applied to generate landslide susceptibility zonation studies ${ }^{31,33,34}$. The factors which are used in the models; topography, slope inclination, aspect are prepared from topographic maps by digitizing contour line to prepare digital elevation model of the area is using ArcGIS 10.2 software. The DEM was used as source layer to analyze slope and aspect of the lower Jalal Basin. Land-use have been selected as a significant layer and prepared from satellite images. The other factors such as lithology, geological structures, and transport network themes were prepared for the landslide susceptibility modeling. Ayalew and Yamagishi $(2005)^{35}$ and by Yalcin $(2011)^{31}$ were specified that there are no parity in the selection of predictive variables for the landslides susceptibility modeling. In the present study landslide frequency ratio (LFR) has been used for the susceptibility analysis. The mathematical expression of LFR as follows:

$L F R=\frac{\mathrm{ALc} / \mathrm{NLS}}{\Sigma A L / \Sigma N L S}$

where ALc represents the percentage of area in the category to the total area; NLs is the percentage of total landslides observed in the category. The denominator is ratio of total area of the study to sum of the observed landslides. To calculate the landslide susceptibility index (LSI), a summation of the LFR of each class was done subsequently using the equation:

$L S I=\sum_{1}^{N} L F R$

LSI values range from 0 to 11.34 in the area. A higher LSI value represents higher landslide susceptibility and lower LSI value shows vice-versa. 
Characteristics of Large Landslides and Application of Frequency Ratio Model for Susceptibility Assessment, Lower Jalal Catchment (Himachal Pradesh)

Table2. Calculation of weightages for Landslide susceptibility index (LSI)

\begin{tabular}{|c|c|c|c|c|c|c|c|}
\hline Data Layers & Categories & $\begin{array}{l}\text { Area } \\
(\mathbf{k m 2})\end{array}$ & $\%$ Area & $\begin{array}{l}\text { Observed } \\
\text { Landslide }\end{array}$ & $\begin{array}{l}\text { \% Observed } \\
\text { Landslide }\end{array}$ & $\begin{array}{l}\text { Observed } \\
\text { Ratios }\end{array}$ & Weightages \\
\hline \multirow{5}{*}{$\begin{array}{l}\text { Relative relief } \\
\text { (m) }\end{array}$} & $0-30$ & 15.32 & 21.18 & 0 & 0.00 & 0 & 0.00 \\
\hline & $30-60$ & 28.61 & 39.55 & 5 & 14.71 & 2.69 & 5.72 \\
\hline & $60-90$ & 18.56 & 25.66 & 7 & 20.59 & 1.25 & 2.65 \\
\hline & $90-120$ & 5.1 & 7.05 & 16 & 47.06 & 0.15 & 0.32 \\
\hline & $>120$ & 4.74 & 6.55 & 6 & 17.65 & 0.37 & 0.79 \\
\hline \multirow{5}{*}{$\begin{array}{l}\text { Slope } \\
\text { (inclination in } \\
\text { degrees) }\end{array}$} & $0-15$ & 14.25 & 19.70 & 0 & 0.00 & 0.00 & 0.00 \\
\hline & $15-25$ & 31.13 & 43.04 & 3 & 8.82 & 4.88 & 10.38 \\
\hline & $25-34$ & 22.17 & 30.65 & 6 & 17.65 & 1.74 & 3.70 \\
\hline & $35-45$ & 3.74 & 5.17 & 21 & 61.76 & 0.08 & 0.18 \\
\hline & $>45$ & 1.04 & 1.44 & 3 & 8.82 & 0.16 & 0.35 \\
\hline \multirow{5}{*}{$\begin{array}{l}\text { Aspect (Slope } \\
\text { direction) }\end{array}$} & Flat & 8.4 & 11.61 & 0 & 0.00 & 0.00 & 0.00 \\
\hline & North & 16.7 & 23.09 & 9 & 26.47 & 0.87 & 1.86 \\
\hline & East & 18.23 & 25.20 & 7 & 20.59 & 1.22 & 2.60 \\
\hline & West & 12.87 & 17.79 & 6 & 17.65 & 1.01 & 2.15 \\
\hline & South & 16.13 & 22.30 & 12 & 35.29 & 0.63 & 1.34 \\
\hline \multirow[t]{3}{*}{ Lithology } & AVMVF & 14.21 & 19.65 & 0 & 0.00 & 0.00 & 0.00 \\
\hline & SST & 25.6 & 35.39 & 23 & 67.65 & 0.52 & 1.11 \\
\hline & TKB & 32.52 & 44.96 & 11 & 32.35 & 1.39 & 2.96 \\
\hline \multirow{5}{*}{$\begin{array}{l}\text { Surface } \\
\text { Dissection }\end{array}$} & $0-0.04$ & 4.56 & 6.30 & 0 & 0.00 & 0.00 & 0.00 \\
\hline & $0.04-0.09$ & 39.91 & 55.18 & 0 & 0.00 & 0.00 & 0.00 \\
\hline & $0.09-0.13$ & 22.68 & 31.36 & 2 & 5.88 & 5.33 & 11.34 \\
\hline & $0.13-0.18$ & 4.85 & 6.71 & 24 & 70.59 & 0.09 & 0.20 \\
\hline & $0.18-0.23$ & 0.36 & 0.50 & 8 & 23.53 & 0.02 & 0.05 \\
\hline \multirow{3}{*}{$\begin{array}{l}\text { Distance to } \\
\text { drainage }(\mathrm{m})\end{array}$} & $0-50$ & 6.3 & 8.71 & 17 & 50.00 & 0.17 & 0.37 \\
\hline & $50-100$ & 11.8 & 16.31 & 9 & 26.47 & 0.62 & 1.31 \\
\hline & $>100$ & 54.23 & 74.98 & 8 & 23.53 & 3.19 & 6.78 \\
\hline \multirow[t]{6}{*}{$\begin{array}{l}\text { Land use / } \\
\text { Land cover }\end{array}$} & $\begin{array}{l}\text { Agriculture } \\
\text { land }\end{array}$ & 7.48 & 10.34 & 2 & 5.88 & 1.76 & 3.74 \\
\hline & Wasteland & 5.68 & 7.85 & 9 & 26.47 & 0.30 & 0.63 \\
\hline & $\begin{array}{l}\text { Sparse } \\
\text { forest }\end{array}$ & 18.39 & 25.43 & 5 & 14.71 & 1.73 & 3.68 \\
\hline & Forest & 32.7 & 45.21 & 11 & 32.35 & 1.40 & 2.97 \\
\hline & Scrubs & 6.2 & 8.57 & 7 & 20.59 & 0.42 & 0.89 \\
\hline & Settlement & 1.88 & 2.60 & 0 & 0.00 & 0.00 & 0.00 \\
\hline \multirow{3}{*}{$\begin{array}{ll}\text { Road } & \text { Buffer } \\
(\mathrm{m}) & \end{array}$} & $0-25$ & 2.7 & 3.73 & 22 & 64.71 & 0.06 & 0.12 \\
\hline & $25-50$ & 6.87 & 9.50 & 2 & 5.88 & 1.61 & 3.44 \\
\hline & $>50$ & 62.76 & 86.77 & 10 & 29.41 & 2.95 & 6.28 \\
\hline
\end{tabular}

\section{RESUlt AND Discussion}

\subsection{Characteristics of Landslides}

The combined area of the landslides occurred in the area is 7.87 hectare; it is around $0.11 \%$ of the total area of the catchment. In the study area, it was found that most of the landslides have occurred in the middle slope category inclined to the south and south-east slope directions. These slopes receive $950-1250 \mathrm{~mm}$ rainfall annually. The slope modification due to the construction of roads and agriculture practices sometimes lead to land degradation that ultimately induces failure failures ${ }^{36}$. In the present study, it was assessed the importance of geomorphic processes such as drainage density and dissection index of the area has been significant with the size and landsliding pattern. The types of landsliding are varying to the specific locations. Some of these slides were observed along the road section transverse by the streams witness complex failures. The pattern of landslides was also related to the slope direction. Particularly, south and south-east, south-west facing slope have received the majority of the observed landslides in the area. Debris fall and slides have mostly confined along the road, while debris flows were limited to the streams. Soils vary from light clay to heavy clay, sandy to sandy loam. The Lower Jalal catchment receives rainfall in monsoon seasons in some prolonged spells. It has caused large slip and failures due to increasing incumbent load on a slope. The density of landslides is found high in the open/ barren land slopes in contrast to a forested area. 


\subsection{Landslide Hazard Susceptibility}

The LSI calculated using the LFR model of the study are from the selected predictive variables have been classified in the five categories of the susceptibility (Fig. 4). The high landslide susceptible area is delineated along the road, stream and barren land and scrubland topographies. The lowest susceptible zones were limited to the broad river valley and forested slopes. The landslide datasets which was not used for the calculation of weights in the LFR model was used for the validation of result. The validation results show the $87 \%$ accuracy of the model for the zonation of landslide susceptible zones in the study area. It was also remarkable to point out that, the area which is inaccessible for the surveys; remote sensing data can be used for the inventory mapping as a basic input for the modeling of landslide hazard zonation and analysis of the probability of land degradation in the catchment. The model was verified, and it was finding that most of the present slope failure sites appear in the high landslide susceptible zone. Fig. 4 shows that most of the susceptible zone is spread on the right side slopes of Jalal River. Table 2 shows the landslides susceptible are delineated using the LFR model. Approximately, $44 \%$ area is classified in the moderate susceptible area and $17 \%$ under high unstable slope category. These areas have observed the highest concentration of observed landslides. Particularly, these slopes are more exposed to the natural process of denudation. Agriculture, open area and barren land are the dominant land cover of this zone. It was investigated that landslide induced displaced materials was around $0.37 \%$ of the total area had been degraded. Total $54790 \mathrm{~m}^{3}$ debris displaced and damaged forest, soil, crops, road, etc.

Table2. Areal distribution of Landside Susceptible zones, Lower Jalal.

\begin{tabular}{|l|l|l|l|}
\hline Description & Area (km) & \% Area & Landslide Occurred \\
\hline Least Susceptible & 0.14 & 0.20 & 0 \\
\hline Low Susceptible & 9.70 & 13.71 & 2 \\
\hline Medium Susceptible & 43.93 & 62.09 & 20 \\
\hline High Susceptible & 16.97 & 23.98 & 11 \\
\hline Very High Susceptible & 0.01 & 0.01 & 3 \\
\hline Total & 70.76 & 100.00 & 36 \\
\hline
\end{tabular}

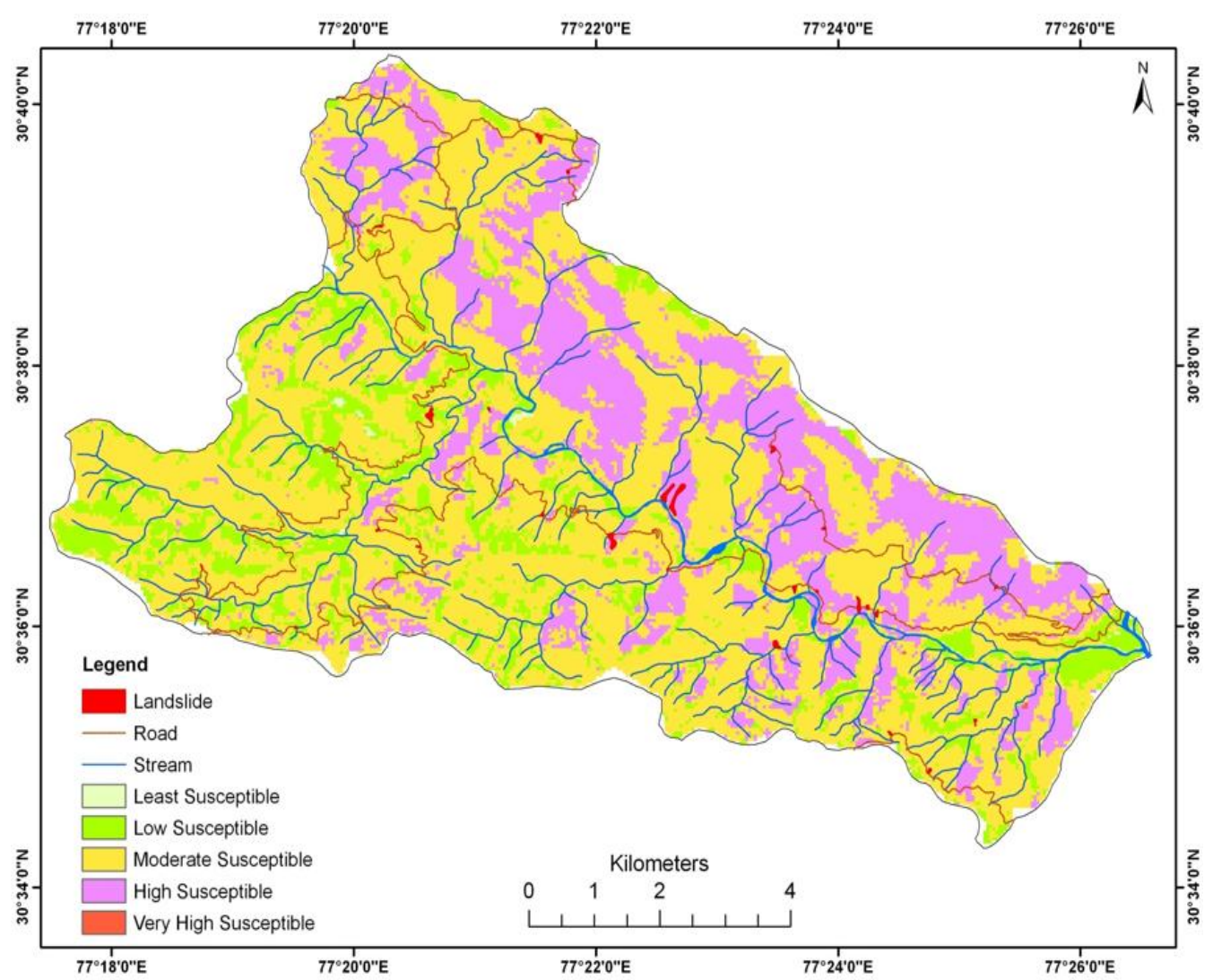

Fig4. Landslide Susceptibility Zones of the study area based on the Landslide Frequency Ratio (LFR) method. 


\section{CONCLUSION}

Landslides that have occurred in the area have long-term geomorphic impacts on the Lower Jalal catchment. It was observed that most of the area has medium to high probability of slope failure. The areas which have medium slope inclination and base surface quartzite, conglomerate lithology are more prone to landsliding in the area. This has influenced surface erosion, and it was accelerated by these slope failures and also increases sediment transfer. The overall land degradation in the valley has influenced by the slope failures, one of the big reason for the progressive occurrence of the landslide. The landslide frequency ration has produced highly accurate landslide susceptibility zones. The validation results suggest that it has $87 \%$ accuracy. Hence, it is suggested that LFR model can be successfully applied in the area for the landslide susceptibility mapping and policy implications for the slope stabilization measures.

\section{ACKNOWLEDGEMENT}

The research work was funded by Department of Science and Technology (DST), Government of India, New Delhi vide project grant (NO.F.15-6(DEC. 2009). KK Sharma is also grateful to Principal Kirori Mal College, the University of Delhi, for providing the research facilities and District Administration, Revenue and PWD, District Sirmour for providing the landslide database and technical support.

\section{REFERENCE}

[1] Sudmeier-Rieux, K., Jaquet, S., Derron, M. H., Jaboyedoff, M. \& Devkota, S. A case study of coping strategies and landslides in two villages of Central-Eastern Nepal. Appl. Geogr. 32, 680-690 (2012).

[2] Pandey, V. K. Predictive landslide susceptibility assessment using the weight-of-evidence method in north-central Garhwal Himalaya, India. Phys. Geogr. 36, 510-536 (2015).

[3] Ayalew, L. \& Yamagishi, H. The application of GIS-based logistic regression for landslide susceptibility mapping in the Kakuda-Yahiko Mountains, Central Japan. Geomorphology 65, 15-31 (2005).

[4] Das, I., Sahoo, S., van Westen, C., Stein, A. \& Hack, R. Landslide susceptibility assessment using logistic regression and its comparison with a rock mass classification system, along a road section in the northern Himalayas (India). Geomorphology 114, 627-637 (2010).

[5] Carrara, A, Guzzetti, F., Cardinali, M. \& Reichenbach, P. Use of GIS technology in the prediction and monitoring of landslide hazard. Nat. Hazards 20, 117-135 (1999).

[6] Mwaniki, M. W., Agutu, N. O., Mbaka, J. G., Ngigi, T. G. \& Waithaka, E. H. Landslide scar/soil erodibility mapping using Landsat TM/ETM+ bands 7 and 3 Normalised Difference Index: A case study of central region of Kenya. Appl. Geogr. 64, 108-120 (2015).

[7] Lee, S. Comparison of landslide susceptibility maps generated through multiple logistic regression for three test areas in Korea. Earth Surf. Process. Landforms 32, 2133-2148 (2007).

[8] Chen, Y. C., Chang, K. T., Lee, H. Y. \& Chiang, S. H. Average landslide erosion rate at the watershed scale in southern Taiwan estimated from magnitude and frequency of rainfall. Geomorphology 228, 756764 (2015).

[9] Chung, C. J. F. \& Fabbri, A. G. Probabilistic prediction models for landslide hazard mapping. Photogramm. Eng. Remote Sensing 65, 1389-1399 (1999).

[10] Lee, S. \& Talib, J. A. Probabilistic landslide susceptibility and factor effect analysis. Environ. Geol. 47, 982-990 (2005).

[11] Lee, S. \& Pradhan, B. Probabilistic landslide hazards and risk mapping on Penang Island, Malaysia. J. Earth Syst. Sci. 115, 661-672 (2006).

[12] Kumar, R. \& Anbalagan, R. Landslide susceptibility zonation of Tehri reservoir rim region using binary logistic regression model. Curr. Sci. 108, 1662-1672 (2015).

[13] Pandey, V. K. \& Sharma, M. C. Probabilistic landslide susceptibility mapping along Tipri to Ghuttu highway corridor, Garhwal Himalaya (India). Remote Sens. Appl. Soc. Environ. 8, 1-11 (2017).

[14] Guzzetti, F. et al. Landslide inventory maps: New tools for an old problem. Earth-Science Rev. 112, 42-66 (2012).

[15] Barnard, P. L., Owen, L. A., Sharma, M. C. \& Finkela, R. C. Natural and human-induced landsliding in the Garhwal Himalaya of Northern India. Geomorphology 40, 21-35 (2001).

[16] Barnard, P. L., Owen, L. A., Sharma, M. C. \& Finkel, R. C. Late Quaternary (Holocene) landscape evolution of a monsoon-influenced high Himalayan valley, Gori Ganga, Nanda Devi, NE Garhwal. 
Geomorphology 61, 91-110 (2004).

[17] Martha, T. R., Kerle, N., Jetten, V., van Westen, C. J. \& Kumar, K. V. Characterising spectral, spatial and morphometric properties of landslides for semi-automatic detection using object-oriented methods. Geomorphology 116, 24-36 (2010).

[18] Pradhan, B., Singh, R. P. \& Buchroithner, M. F. Estimation of stress and its use in evaluation of landslide prone regions using remote sensing data. Adv. Sp. Res. 37, 698-709 (2006).

[19] Dahal, R. K. et al. GIS-based weights-of-evidence modelling of rainfall-induced landslides in small catchments for landslide susceptibility mapping. Environ. Geol. 54, 311-324 (2008).

[20] van Westen, C. J., van Asch, T. W. J. \& Soeters, R. Landslide hazard and risk zonation - Why is it still so difficult? Bull. Eng. Geol. Environ. 65, 167-184 (2006).

[21] Pradhan, B., Lee, S. \& Buchroithner, M. F. Use of geospatial data and fuzzy algebraic operators to landslide-hazard mapping. Appl. Geomatics 1, 3-15 (2009).

[22] Ermini, L., Catani, F. \& Casagli, N. Artificial Neural Networks applied to landslide susceptibility assessment. Geomorphology 66, 327-343 (2005).

[23] Kanungo, D. P., Arora, M. K., Sarkar, S. \& Gupta, R. P. A comparative study of conventional, ANN black box, fuzzy and combined neural and fuzzy weighting procedures for landslide susceptibility zonation in Darjeeling Himalayas. Eng. Geol. 85, 347-366 (2006).

[24] Gupta, R. P., Kanungo, D. P., Arora, M. K. \& Sarkar, S. Approaches for comparative evaluation of raster GIS-based landslide susceptibility zonation maps. Int. J. Appl. Earth Obs. Geoinf. 10, 330-341 (2008).

[25] P.K. Champati Ray, I. Parvaiz, R. Jayangondaperumal, V.C. Thakur, V.K. Dadhwal, F. A. B. Analysis of seismicity-induced landslides due to the 8 october 2005 earthquake in Kashmir Himalaya. Curr. Sci. 97, 1742-1751 (2009).

[26] Carrara, A. \& Pike, R. J. GIS technology and models for assessing landslide hazard and risk. Geomorphology 94, 257-260 (2008).

[27] Pantelidis, L. Rock slope stability assessment through rock mass classification systems. Int. J. Rock Mech. Min. Sci. 46, 315-325 (2009).

[28] Goudie, A. S. Global warming and fluvial geomorphology. Geomorphology 79, 384-394 (2006).

[29] Hack, R., Price, D. \& Rengers, N. A new approach to rock slope stability - a probability classification ( SSPC ). Bull. Eng. Geol. Environ. 62, 167-184 (2003).

[30] Selby, M. J. \& Selby, M. J. Rock Mass Strength and the Form of Some Inselbergs in the Central Namib Desert. 7, (1982).

[31] Yalcin, A. A geotechnical study on the landslides in the Trabzon Province, NE, Turkey. Appl. Clay Sci. 52, 11-19 (2011).

[32] Brunetti, M. T. et al. Analysis of a new geomorphological inventory of landslides in Valles Marineris, Mars. Earth Planet. Sci. Lett. 405, 156-168 (2014).

[33] Ding, Q., Chen, W. \& Hong, H. Application of frequency ratio, weights of evidence and evidential belief function models in landslide susceptibility mapping. Geocarto Int. 6049, 1-21 (2016).

[34] Lee, S. \& Pradhan, B. Landslide hazard mapping at Selangor, Malaysia using frequency ratio and logistic regression models. Landslides 4, 33-41 (2007).

[35] Ayalew, L. \& Yamagishi, H. The application of GIS-based logistic regression for landslide susceptibility mapping in the Kakuda-Yahiko Mountains, Central Japan. Geomorphology 65, 15-31 (2005).

[36] Promper, C., Puissant, A., Malet, J. P. \& Glade, T. Analysis of land cover changes in the past and the future as contribution to landslide risk scenarios. Appl. Geogr. 53, 11-19 (2014).

\section{AUTHORS' BIOGRAPHY}

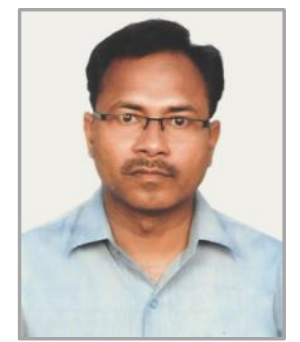

Vijendra Kumar Pandey has completed his M.Phil. and Ph. D. in Geography with specialization in Geomorphology from the Center for the Study of Regional Development, School of Social Sciences, Jawaharlal Nehru University, New Delhi. His research interests are mass movement, geomorphological processes, glacier dynamics, climate change \& disaster management. He has been working as Post-doctoral Research Associate in a DST sponsored project on Himalayan Cryosphere: Science and Society, IUCCC at Center for the Study of Regional Development, School of Social Sciences, Jawaharlal Nehru University, New Delhi. He has published many research papers on natural hazards and advanced application of Geoinformatics in peer reviewed journals of International repute. 


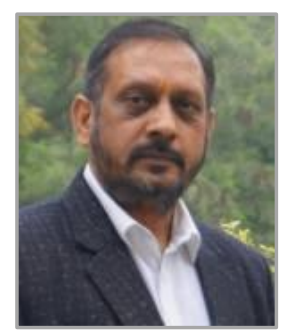

Kaushal Kumar Sharma is Professor of Geography at Center for the Study of Regional Development, School of Social Sciences, Jawaharlal Nehru University, New Delhi. He was completed his Ph. D. in Geography at Department of Geography, Delhi School of Economics, Delhi University, Delhi. He taught Geography at Kirori Mal College for 32years andhas vast research experience. He has completed many research projects on Natural hazard, Development Planning, Policy and Decision Making sponsored by DST, UGCand State Governments. He has also completed a mega project for the rural development and micro-enterprise with SEWA-THD Cat Deengoan, Uttarakhand. He has also been provided consultancy for the implementation of Corporate Social Responsibility (CSR) for the Public Sector Undertakings.

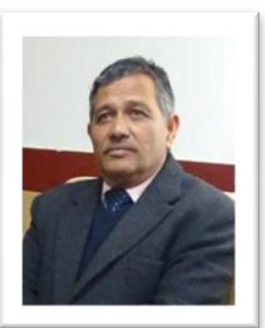

Suresh Kumar Bandooni is Associate Professor at Department of Geography, ShaheedBhagat Singh (Eve) College, Delhi University, Delhi. He was completed his Ph. D. in Geography at Department of Geography, Delhi School of Economics, Delhi University, Delhi. He has been completed many research projects and presented more than 40 research papers in the National and International conferences and seminar. He has published many research papers book chapters and edited books on Disaster Management, Risk Assessment, Development Planning and Environmental issues. He has done three major projects sponsored by DST and three projects of UGC. Presently he is also working as Project Director of an action project sponsored by SEWA-THDC.

Citation: Vijendra Kumar Pandey, Kaushal Kumar Sharma, Suresh Kumar Bandooni. Characteristics of Large Landslides and Application of Frequency Ratio Model for Susceptibility Assessment, Lower Jalal Catchment (Himachal Pradesh). International Journal of Research in Geography. vol 4, no. 1, 2018, pp. 1726. doi:http://dx.doi.org/10.20431/2454-8685.0401004.

Copyright: (0) 2018 Authors. This is an open-access article distributed under the terms of the Creative Commons Attribution License, which permits unrestricted use, distribution, and reproduction in any medium, provided the original author and source are credited. 